\title{
Spatial regulation and organization of DNA replication within the nucleus
}

\author{
Toyoaki Natsume • Tomoyuki U. Tanaka
}

Published online: 24 October 2009

(C) The Author(s) 2009. This article is published with open access at Springerlink.com

\begin{abstract}
Duplication of chromosomal DNA is a temporally and spatially regulated process. The timing of DNA replication initiation at various origins is highly coordinated; some origins fire early and others late during $\mathrm{S}$ phase. Moreover, inside the nuclei, the bulk of DNA replication is physically organized in replication factories, consisting of DNA polymerases and other replication proteins. In this review article, we discuss how DNA replication is organized and regulated spatially within the nucleus and how this spatial organization is linked to temporal regulation. We focus on DNA replication in budding yeast and fission yeast and, where applicable, compare yeast DNA replication with that in bacteria and metazoans.
\end{abstract}

Keywords DNA replication · replication origin · replication fork $\cdot$ replisome $\cdot$ replicon $\cdot$ replication focus $\cdot$ replication factory
Abbreviations
BrdU BromodeoxyUridine
CDK Cyclin-dependent kinase
ORC Origin recognition complex

Responsible Editors: Marie-Nicolle Prioleau and Dean Jackson

T. Natsume $\cdot$ T. U. Tanaka $(\bowtie)$

Wellcome Trust Centre for Gene Regulation

and Expression, University of Dundee,

Dundee DD1 5EH, UK

e-mail: t.tanaka@lifesci.dundee.ac.uk
PCNA Proliferating cell nuclear antigen

preRC Prereplicative complex

rDNA Ribosomal DNA

RFC Replication factor C

RPA Replication protein A

Sir Silent information regulator

SPB Spindle pole body (microtubule-organizing center in yeast)

TK Thymidine kinase

\section{Introduction}

DNA replication initiates at multiple replication origins along linear chromosomes in eukaryotes. Each origin generates a pair of sister replication forks that subsequently move along parental DNA in a bidirectional manner to undergo DNA replication. Replication forks then terminate when they encounter forks from the adjacent replication origins moving in the opposite direction. Thus, replication initiated at each origin leads to duplication of a discrete DNA region, which is called replicon.

In budding yeast Saccharomyces cerevisiae, DNA replication origins are defined by a 200 -bp DNA sequence called an autonomously replicating sequence, which was originally identified based on its ability to support the replication of plasmid DNA (Newlon and Theis 1993). The budding yeast genome (about $14 \mathrm{Mb}$ ) contains $\sim 300$ replication 
origins at average intervals of $\sim 50 \mathrm{~kb}$ (Raghuraman et al. 2001; Wyrick et al. 2001; Yabuki et al. 2002; Feng et al. 2006; Nieduszynski et al. 2006).

In fission yeast Schizosaccharomyces pombe, replication origins lack a consensus DNA sequence but consist of AT-rich sequences (Robinson and Bell 2005). It is estimated that at least half of the approximately 2,500 intergenic regions have potential origin activity (Dai et al. 2005), and 460 of these are actually licensed for replication (Hayashi et al. 2007). Metazoan cells also lack any DNA consensus sequence for replication origins (Robinson and Bell 2005), but intriguingly, the initiation points of replication at the nucleotide level show very similar distribution patterns within the origin regions in budding yeast, fission yeast, and humans (Bielinsky and Gerbi 2001).

Despite the difference in the DNA sequences of replication origins between yeast and metazoa, the protein components assembling at replication origins and replication forks show remarkable structural similarities (Bell and Dutta 2002). The prereplicative complex (preRC) is a large protein complex, comprised of the origin recognition complex (ORC), Cdc6, Cdt1, and Mcm2-7 (Blow and Dutta 2005). The preRC is formed at replication origins from telophase and throughout G1 phase to license the origins for DNA replication initiation. At the onset of $\mathrm{S}$ phase, more proteins such as DNA polymerases and a sliding clamp called proliferating cell nuclear antigen (PCNA) are loaded at origins, establishing a protein complex called the replisome, which subsequently moves with a replication fork to undergo DNA replication (Johnson and O'Donnell 2005).

Replication of chromosomal DNA is a highly regulated process both in space and time. DNA replication initiation at various origins (origin firing) occurs by a coordinated temporal program; some origins fire early and others late during $\mathrm{S}$ phase. Inside the nuclei, duplication of chromosomal DNA is physically organized into replication factories, consisting of DNA polymerases and other replication proteins. In this review article, we examine the spatial organization and regulation of DNA replication within the nucleus and discuss how this spatial organization is linked to temporal regulation. We focus on DNA replication in budding yeast and fission yeast and, in chosen topics, compare yeast DNA replication with that in bacteria and metazoans. In this context, we briefly touch upon spatial regulation of DNA damage and replication checkpoints, which are, however, reviewed in more detail in Herrick and Bensimon (2008) and Branzei and Foiani (2009).

\section{Subnuclear localization of replication origins and timing of their firing}

When replication origins are isolated and placed on minichromosomes, they normally replicate in early $\mathrm{S}$ phase in budding yeast (Ferguson and Fangman 1992). However, in their normal chromosomal context, some origins show delayed firing within $\mathrm{S}$ phase. This delay is due to proximal cis-acting chromosomal elements, telomeres, and other DNA sequences for subtelomeric and nontelomeric late-firing origins, respectively (Ferguson and Fangman 1992; Friedman et al. 1996). So far, among such cis-acting chromosomal elements, no consensus DNA sequences, apart from telomeres, have been identified.

It has been shown that both subtelomeric and nontelomeric late-firing origins localize preferentially in the nuclear periphery during G1 phase (Heun et al. 2001). Does this nuclear periphery localization have a causative role in the late firing of replication origins during $\mathrm{S}$ phase? Indeed, in various conditions, the nuclear periphery localization of origins is correlated with their delayed replication. For example, cis-acting chromosomal elements, which determine the late firing of the origins, are also required for nuclear periphery localization (Friedman et al. 1996; Heun et al. 2001). Moreover, after a subtelomeric late-firing origin was excised from its chromosome locus prior to G1 phase (in G1, telomeres localize preferentially at the nuclear periphery); the origin advanced the timing of its firing to early $\mathrm{S}$ phase (Raghuraman et al. 1997).

However, in some circumstances, late firing of replication origins is not correlated with their nuclear periphery localization during G1. For example, after a normally early-firing origin was tethered to the nuclear periphery by targeted interaction with an integral membrane protein, the origin did not show late firing (Zappulla et al. 2002). Moreover, genetic screening identified mutants that disrupt telomere localization at the nuclear periphery but still maintain late firing of subtelomeric origins (Hiraga et al. 2006). Therefore, nuclear periphery localization of replica- 
tion origins is neither sufficient nor required for their late firing.

It seems that chromatin states and structures, such as silencing by Sir proteins and chromosome-end binding of the $\mathrm{Ku}$ complex, affect more directly the initiation timing of subtelomeric origins (Stevenson and Gottschling 1999; Cosgrove et al. 2002; Zappulla et al. 2002). Sir proteins and the $\mathrm{Ku}$ complex also regulate the nuclear periphery localization of telomeres (Hediger et al. 2002; Taddei and Gasser 2004); however, the nuclear periphery localization is probably not a direct determinant of their replication timing. Perhaps a similar argument can be also applied for nontelomeric late-firing origins, although regulators other than $\mathrm{Sir}$ and $\mathrm{Ku}$ proteins may be involved in delaying their replication. For example, it was shown that histone deacetylase Rpd3 is important for delaying their replication (Vogelauer et al. 2002; Aparicio et al. 2004; Knott et al. 2009); it is known that $\mathrm{Rpd} 3$ is targeted to promoters and coding regions and regulates their transcription (Kadosh and Struhl 1997; Carrozza et al. 2005; Keogh et al. 2005).

In summary, it does not seem that the subnuclear localization of replication origins per se determines their timing of replication initiation in yeast; however, underlying chromatin states and structures probably regulate both their localization and initiation timing. Nonetheless, it is still possible that the subnuclear localization assists maintenance of underlying chromatin states and structures in a feedback and thereby affects replication timing moderately even if it is not an essential determinant.

DNA replication is also regulated temporally and spatially in metazoan cells. For example, euchromatin and heterochromatin undergo DNA replication in early and late $\mathrm{S}$ phase, respectively (Gilbert 2002). Replication timing of a chromosomal region is correlated with its subnuclear localization and with chromatin states such as histone modifications (Hiratani et al. 2009), similarly to yeast. Nonetheless, their causal relationships still remain to be clarified in metazoan cells.

\section{Replisome architecture and association of sister replisomes}

Upon replication initiation, DNA polymerases and other replication proteins such as PCNA and replication factor $\mathrm{C}$ assemble at a licensed replication origin, forming a replisome, which subsequently moves together with a replications fork to undergo DNA replication (Johnson and O'Donnell 2005). A range of evidence suggests that each replisome synthesizes both leading and lagging strands of DNA simultaneously (Baker and Bell 1998; Waga and Stillman 1998; Johnson and O'Donnell 2005). In bacteria, one type of DNA polymerase (e.g., DNA polymerase III in Escherichia coli) synthesizes both leading and lagging strands. In contrast, in eukaryotes, the identity of DNA polymerases that synthesize each strand had been unclear until recently. The mutation rates were evaluated using polymerase mutants with reduced replication fidelity in budding yeast, and it was discovered that DNA polymerase $\delta$ and $\varepsilon$ primarily synthesize lagging and leading strands, respectively (Pursell et al. 2007; Nick McElhinny et al. 2008).

It was originally thought that the two replisomes at sister forks (i.e., initiated from the same origin) would behave separately since they travel in opposite directions along template DNA. However, it was found that on bacterial circular chromosomes where DNA replication starts from a single defined origin, sister forks move along DNA and normally complete DNA replication with similar timing at a defined region on the chromosome (Bussiere and Bastia 1999). To explain this coordinated termination of DNA replication, it was proposed that two replisomes at sister forks (sister replisomes) remain attached during DNA replication (Dingman 1974; Falaschi 2000).

This model predicts that template DNA moves into two associated replisomes, and newly replicated sister DNA strands are extruded as replication proceeds. Such DNA motion relative to centrally located stationary replisomes (Lemon and Grossman 1998) was indeed confirmed in bacteria Bacillus subtilis and Caulobacter crescentus (Lemon and Grossman 2000; Jensen et al. 2001; Migocki et al. 2004). Furthermore, electron microscopy of large tumor antigen ( $\mathrm{T}$ antigen) in simian virus 40 , which functions as a DNA helicase at replication forks (Herendeen and Kelly 1996), showed that unwound DNA from viral replication origins forms two loops which are pinched by the same pair of associated T-antigen hexamers (Wessel et al. 1992), thus, supporting the associated replisome model. On the other hand, in E. coli, sister replisomes separate shortly after DNA replication initiation and undergo DNA replication independently 
(Bates and Kleckner 2005; Reyes-Lamothe et al. 2008).

In contrast to bacteria and viruses, it remained unknown until recently whether sister replisomes are associated together in eukaryotes. In budding yeast, live-cell imaging was used to analyze the replication timing of chromosome loci (Fig. 1) (Kitamura et al. 2006), at which bacteria-derived tet $O$ and $l a c O$ arrays were integrated (Straight et al. 1996; Michaelis et al. 1997). These arrays bound TetR and lacI proteins, fused with fluorescent proteins, and were thus visualized as small fluorescent dots. The fluorescent dots increased their intensity upon their DNA replication when the number of tetO and $l a c O$ arrays was



B

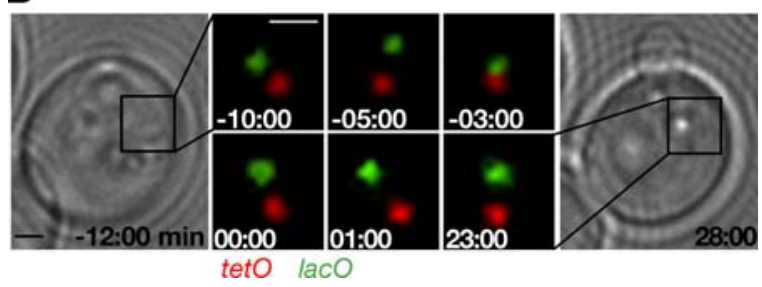

Fig. 1 Sister replisomes are associated with each other during replication in budding yeast. A Model of a closely associated double replisome and expected behavior of two chromosomal loci, tet $O$, and lacO, which bound TetR-3CFP and GFP-LacI, respectively (top). Their chromosomal positions are shown together with replication profile (Raghuraman et al. 2001) of the relevant chromosome region (below). B Two loci come close to each other upon DNA replication. CFP (red), GFP (green), and bright field images of a representative cell are shown. The tet $O$ and $l a c O$ are visualized as small fluorescent of dots of CFP and GFP, respectively. Two loci came close to each other, increased their intensity ( -3 to $1 \mathrm{~min}$ ) and subsequently diverged from each other during $\mathrm{S}$ phase. Scale bar represents $1 \mu \mathrm{m}$. The figure is adapted from Kitamura et al. (2006) with permission (Copyright $($ Clsevier 2006) doubled, which defined their replication timing by microscopy (Kitamura et al. 2006). Using this method, two loci were selected and visualized within a single replicon so that they locate at the opposite sides of the relevant replication origin and show similar replication timing (based on a genome-wide replication timing data: Raghuraman et al. (2001)). Remarkably, these two loci came close to each other, increased their intensity, and subsequently diverged from each other during $\mathrm{S}$ phase (Kitamura et al. 2006). Such behavior of the two loci suggests that sister replisomes are associated together during replication of the replicon. Furthermore, in a separate study, nascent DNA segments were pulse-labeled and observed by electron microscopy. This study suggested that human sister replisomes are also associated with each other during DNA replication (Ligasová et al. 2008).

\section{Possible benefits of the association of sister replisomes}

Why do cells keep sister replisomes closely associated during replication? What benefits can cells reap from it? One possibility is that the close association enables temporal coordination of DNA replication between sister replisomes. Indeed, such temporal coordination was revealed in human cells: by labeling nascent DNA on single-molecule DNA fibers (Michalet et al. 1997; Herrick et al. 2000); it was possible to measure the velocity of replication fork movements along template DNA, and it was found that the majority pairs of sister forks showed very similar velocity (Conti et al. 2007). Intriguingly, if one fork changed its speed, its sister also changed its speed in a similar way. Given that replication forks in the adjacent replicon also shows similar velocity (Conti et al. 2007), this temporal coordination may help replication forks in the same and neighboring replicons change their speed collaboratively and promptly, responding to replication stress such as the reduced amount of deoxy-nucleotides available in the nucleus. The velocity of sister replication forks also show significant correlation in budding yeast (Fig. 2); thus, the temporal coordination seems to be conserved in evolution.

The temporal coordination between associated sister replisomes would be indeed useful for replisomes to 


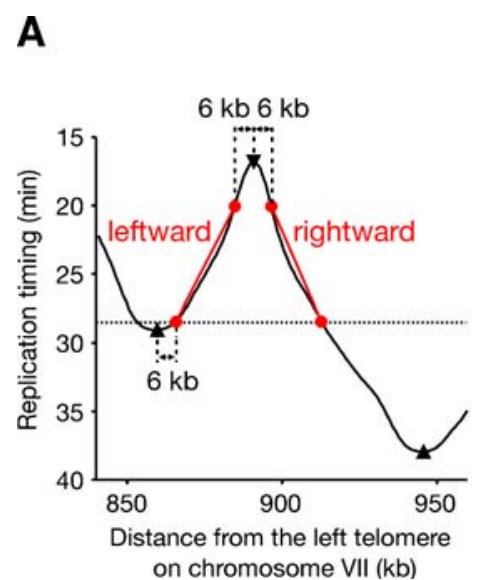

Fig. 2 The velocity of replication fork movements is correlated between sister forks in budding yeast. A A representative example of measuring the velocity. We used the genome-wide replication profile (black line; Yabuki et al. 2002), which represents the time (minutes) after release from $\alpha$ factor arrest at which $50 \%$ of cells complete DNA replication, along the chromosomes (1-kb intervals). Peaks and valleys (rectangles pointing down and up, respectively) of the profile represent replication origins and termini, respectively. To measure the velocity, first, we excluded a 5 -kb region on each side of peaks and valleys in order to avoid errors due to smoothing when drawing the replication profile in that region. Second, the regions were selected for measurement of the velocity of the leftward and rightward forks (red lines) so that they end with

respond promptly to replication stress if this stress affects the whole genome. On the other hand, it may be rather harmful if the replication stress is imposed locally on particular chromosome loci. For example, when DNA damage on a chromosomal region halts or terminates the motion of a fork (Branzei and Foiani 2005), the behavior of its sister fork would be also affected, widening the adverse effects of the DNA damage. Intriguingly, however, it was shown that in yeast cells, a replication fork continues to move while its sister fork is halted or terminated due to a DNA double-strand break (Doksani et al. 2009). Similarly, within yeast rDNA regions, halting of a replication fork by a replication-fork barrier did not stop or slow down the progression of its sister fork (Brewer and Fangman 1988; Linskens and Huberman 1988). Taken together, when a replication fork is stalled upon the encounter on a local replication obstacle, its sister can behave independently. Thus, there might be a mechanism that senses a stalled replication fork and uncouples it functionally from its sister fork (Herrick and Bensimon 2008).

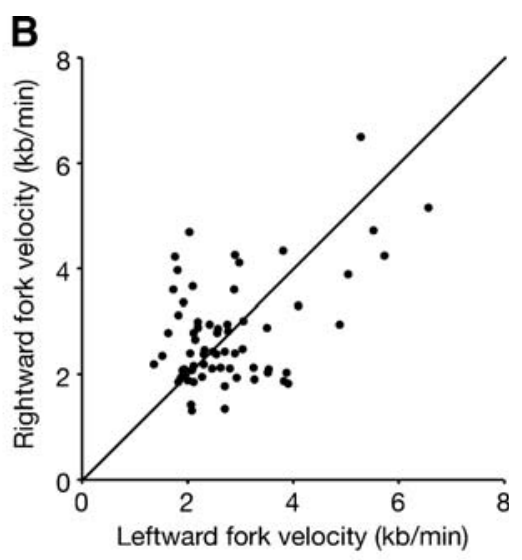

the same replication timing; for example, if the right valley goes deeper than the left, the selected region for the right terminated when the left one ended. Third, we chose replicons for the analysis only when their defined regions for measurement span more than $8 \mathrm{~kb}$ along a chromosome both at left and right sides, as smaller ones may give larger errors. The replicon, locating at $508 \mathrm{~kb}$ on chromosome VIII (from the left telomere), was excluded from the analysis as it showed much larger fork velocity $(11-17 \mathrm{~kb} / \mathrm{min})$ than others. B As described in A, we chose 67 replicons out of 260 identified in Yabuki et al. (2002) and measured the velocity of leftward and rightward forks. The graph indicates that the velocity of replication fork movements shows significant correlation between sister forks (Pearson's correlation, $r=0.4725, p<0.0001, N=67$ )

Are there any other functional consequences or benefits of the association of sister replisomes? Another possible benefit is to avoid only a half of a replicon being replicated. Once a replication origin is unwound and replication forks are generated, the origin loses its ability to initiate replication, which requires preRC formation at the origin in eukaryotes (see "Introduction") and the origin methylation on both DNA strands in bacteria (Boye et al. 2000). Therefore, a half replicon might fail to replicate if one replisome could initiate without waiting for the other replisome to be loaded onto the origin. If avoidance of this problem is a major benefit of associated sister replisomes, this association might not be necessary once both of them start DNA replication from an origin. Indeed, at least in bacterium E. coli, sister replisomes separate shortly after initiation and undergo DNA replication independently (Bates and Kleckner 2005; Reyes-Lamothe et al. 2008). Nonetheless, in other bacteria such as B. subtilis and C. crescentus, or in eukaryotes such as budding yeast and humans, sister replisomes seem to be associated for a longer time, 
perhaps throughout replication of the whole replicon (see above).

Another possible benefit of associated sister replisomes might be spatial coordination of DNA replication. The associated sister replisomes may coordinate the DNA polymerase operation for two leading and two lagging strands to avoid chromosome entanglement and to facilitate smooth reeling in and out of unreplicated and replicated DNA strands. This spatial coordination might be particularly important in eukaryotic cells, in which more complex spatial regulation may be required as their multiple replicons are processed for DNA replication in a single replication factory (see below).

\section{Replication foci and replication factory}

When mammalian cells are pulse-labeled with nucleoside analogs (such as bromodeoxyuridine (BrdU)) or tagged nucleotides during $\mathrm{S}$ phase, DNA replication appears to start at several discrete sites called "replication foci" (Nakamura et al. 1986; Nakayasu and Berezney 1989). Studies with different mammalian cell lines showed that 100-1,000 foci are observed in early S-phase nuclei (Berezney et al. 2000). It is estimated that each focus contains 10-100 replicons, which together represent a chromatin territory, a stable unit maintained until the next cell cycle (Jackson and Pombo 1998). The average replication focus is estimated to contain $\sim 1 \mathrm{Mbp}$ of genomic DNA in mouse cells (Ma et al. 1998).

Similar replication foci were also observed in budding yeast nuclei. In vitro experiments using isolated yeast nuclei showed that a tagged nucleotide was incorporated as 15-20 discrete foci in an ORCdependent and origin-specific manner (Pasero et al. 1997). Because yeast cells lack a thymidine kinase (TK), they cannot utilize BrdU or isotope-labeled thymidine, which is widely used to visualize sites of DNA replication in intact mammalian cells. However, introduction of heterogeneous TK enabled yeast cells to incorporate BrdU in vivo (McNeil and Friesen 1981; Lengronne et al. 2001; Vernis et al. 2003). With this method, several studies have shown that BrdU is incorporated as discrete foci into nuclei using immunostaining (Lengronne et al. 2001; Hiraga et al. 2005; Kitamura et al. 2006). In budding yeast, however, it is unlikely that replication foci represent stable chroma- tin units maintained to the next cell cycle, in contrast to mammalian cells (see above). In fact, a chromosome arm locus can move vigorously covering a wide area of the yeast nucleus in a single cell cycle (Berger et al. 2008; our unpublished results). This is presumably due to the small size of the yeast nucleus (see Fig. 3) and may also reflect potentially different chromatin organization between yeast and mammalian cells.

When replisome components such as DNA polymerase a and PCNA are visualized by immunolabeling in mammalian cells, they show discrete punctate signals in the nucleus during $\mathrm{S}$ phase (Frouin et al. 2003). These punctate signals are called "replication factories" as they colocalize with replication foci, i.e., the sites of ongoing DNA replication; thus, replisome components are concentrated into discrete foci, in which multiple replicons are processed for replication (Hozák et al. 1993). The organization and dynamics of replication factories were also examined in live mammalian cells that expressed PCNA, fused with a fluorescent protein, (Leonhardt et al. 2000; Somanathan et al. 2001). Live-cell imaging revealed that replication

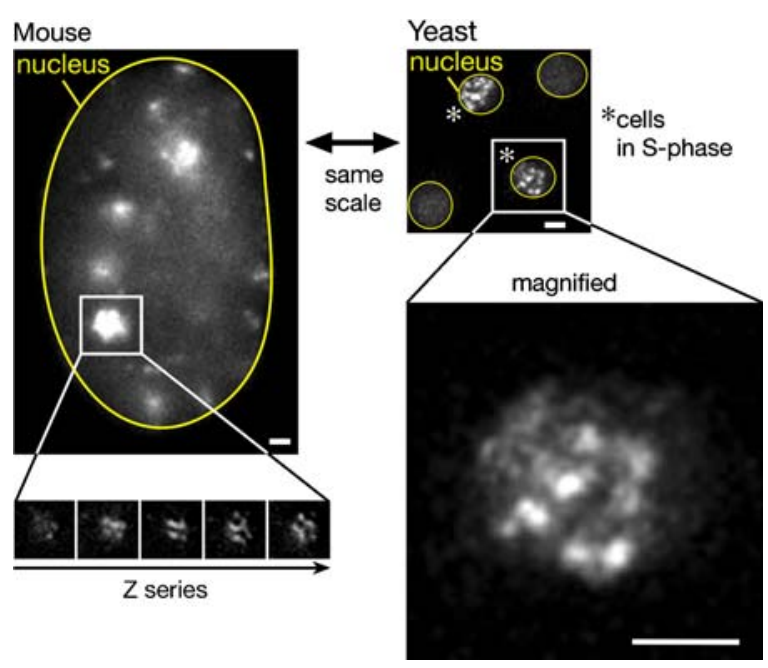

Fig. 3 Comparing the size of replication factories and the nucleus between budding yeast and mammalian cells. The subnuclear localization of PCNA fused with GFP during S phase in a mouse cell (top left; scale bar $1 \mu \mathrm{m}$; adapted from (C) Leonhardt et al. (2000) with permission) and in budding yeast (top right, asterisks; scale bar $1 \mu \mathrm{m}$ ). A magnified image of the yeast nucleus is also shown (bottom right). The nuclei of yeast and mouse cells are outlined in yellow for comparison of their sizes. Note that a large factory is composed of several small ones in a mouse cell (Leonhardt et al. 2000; Z series, bottom left) 
factories show dynamic assembly and disassembly throughout $\mathrm{S}$ phase.

Replication factories are also formed in the nucleus of budding yeast, as revealed by immunostaining and live-cell imaging (Ohya et al. 2002; Hiraga et al. 2005; Kitamura et al. 2006). For example, when PCNA or DNA polymerases $\alpha$ and $\varepsilon$ were visualized with fluorescent proteins, yeast cells showed 10-15 globular signals in their nuclei during $S$ phase (Kitamura et al. 2006). The size of each globular signal, i.e., replication factory, was up to $200 \mathrm{~nm}$ in diameter, which is smaller than the $0.5-2-\mathrm{mm}$ diameter replication factories of mammalian cells (Leonhardt et al. 2000; Fig. 3). However, given that large factories are composed of several small ones in mammalian cells (Leonhardt et al. 2000), yeast factories may correspond to the small units of mammalian factories in terms of the size and mode of function. Replication factories in yeast change their shapes and show dynamic assembly and reassembly, similarly to mammalian cells. These replication factories at least partially colocalize with replication foci, visualized with pulse-labeled BrdU, in fixed cells (Hiraga et al. 2005; Kitamura et al. 2006). Furthermore, when a tet $O$ array (bound by TetR fusion with a fluorescent protein) was visualized as a small fluorescent dot on a chromosome locus, the dot increased its intensity specifically upon colocalization with a replication factory, thus, confirming de novo DNA replication at factories in live cells (Kitamura et al. 2006). Fission yeast nuclei also show globular signals of PCNA and DNA polymerase $\alpha$ during S phase (Meister et al. 2005, 2007; Natsume et al. 2008).

\section{Replication factories: regulation, organization, and possible benefits}

Is a replication factory a preformed complex, inside of which replication is initiated? Alternatively, only after replication initiation, is the factory formed as a result of assembly of replisomes undergoing replication? A number of evidences suggest that the factory is formed only after DNA replication initiation. For example, the factory formation is dependent on the activity of cyclin-dependent kinase (CDK) 2 that triggers DNA replication initiation in vertebrate cells (Cardoso et al. 1993; Jackson et al. 1995; Yan and Newport 1995). On the other hand, punctate signals of replication protein A (RPA) appear prior to DNA replication in Xenopus egg extract system (Adachi and Laemmli 1992, 1994). However, it turns out that RPA, which binds single-strand DNA with dependence on preRC (and therefore, directly relevant to DNA replication), forms factories only after replication initiation in S phase (Jackson et al. 1995; Yan and Newport 1995; Dimitrova et al. 1999).

Replication factories are also formed after replication initiation in yeast cells, where the factory formation is delayed if the activation of S-phase CDK is retarded (Kitamura et al. 2006). Furthermore, if the origin licensing becomes defective in yeast cells by depletion of $\mathrm{Cdc} 6$, the factory formation is abolished even if other S-phase events such as Sphase CDK activation takes place normally. These results suggest that in cells ranging from yeast to vertebrates, the assembly of active replisomes undergoing DNA replication leads to the formation of replication factories.

As discussed above, replication factories show dynamic assembly and disassembly during $\mathrm{S}$ phase. As a result, how do factories change their organization in the nucleus? In mammalian cells, a large number of factories are distributed throughout the nucleus, except for the nucleolus, during early $\mathrm{S}$ phase. During mid S phase, they appear at the periphery of the nucleus, where heterochromatin is enriched. Then, in late $\mathrm{S}$ phase, large factories, composed of several independent small ones (see Fig. 3), are formed inside the nucleus (Leonhardt et al. 2000). The change in the distribution of replication factories was also examined in fission yeast (Meister et al. 2007). After the onset of $S$ phase, factories appear throughout the nucleus except for the nucleolus. Later in S phase, large factories appear at the edge of the nucleolus. Interestingly, this temporal pattern is regulated by Cds1 (Chk2) kinase, a regulator of Sphase checkpoint, even in the absence of replication stress (Meister et al. 2007). In vertebrate cells, it was shown that another checkpoint kinase Chk1 is involved in temporal pattern of origin firing during unperturbed S phase (Maya-Mendoza et al. 2007). When DNA replication is halted due to replication stress, the replication checkpoint pathway is also required to maintain the organization of replication factories (Dimitrova and Gilbert 2000).

In mammalian cells, a replication focus is considered to represent a cluster of multiple replicons (10- 
100) that synchronously fire in S phase, although the number of replicons per focus and its synchrony seem to be highly heterogeneous (Berezney et al. 2000). What group of replicons forms a replication focus that is processed for replication in a single replication factory? Intriguingly, as S phase proceeds, a replication focus appears in close proximity to a focus replicating earlier, suggesting that replication may proceed to neighboring regions by a domino effect involving local changes of chromatin states (Sporbert et al. 2002; Sadoni et al. 2004). In budding yeast, neighboring replicons along a chromosome region can be grouped into clusters, each of which comprises several origins that initiate replication with similar timing and behave similarly after deletion of an Sphase cyclin (Yabuki et al. 2002; McCune et al. 2008). The origins in the same cluster might be processed in the same replication factory. On the other hand, replicons on different chromosomes, such as those at centromere or telomere regions (see below), might be processed in the same factory due to their proximity in the nucleus.

Are there any benefits of forming replication factories and undergoing replication at discrete sites? One possible benefit might be that by concentrating replisome components and DNA-building materials such as deoxy-nucleotides, cells may increase the efficiency of DNA replication. In addition, a group of replicons processed in each replication factory may form a unit that responds coordinately to a replication stress or DNA damage. For example, it is suggested that under a replication stress, the replication initiation from dormant origins is promoted within the factories that have been already formed while replication initiation is suppressed outside of these factories (Ge et al. 2007). Moreover, when the speed of replication forks changes, this affects the programming of origin firing in the next cell cycle (Courbet et al. 2008), in which replication factories may signal a change of the fork speed.

\section{DNA replication at centromeres and telomeres}

In this section, we briefly discuss DNA replication at centromeres and telomeres as examples of spatial regulation of replication in particular chromosome contexts. In budding yeast, spindle pole bodies (SPBs; microtubule-organizing centers in yeast) are embedded in the nuclear envelope, which remains intact throughout the cell cycle (closed mitosis; Heath 1980), and kinetochores are tethered to SPBs by microtubules during most of the cell cycle. However, it was revealed that, upon centromere DNA replication, kinetochores are transiently disassembled, causing centromere detachment from microtubules for 12 min (Kitamura et al. 2007). Subsequently kinetochores are reassembled and interact with microtubules again. Because centromeres are replicated in early $\mathrm{S}$ phase in budding yeast (McCarroll and Fangman 1988; Raghuraman et al. 2001), centromere detachment and reattachment also happen in early $\mathrm{S}$ phase. The timing of these events is presumably crucial to make a time window sufficient (even in the absence of G2 phase; see below) for establishment of proper kinetochoremicrotubule attachment, prior to chromosome segregation in subsequent anaphase.

Telomeres in budding yeast tend to localize at the nuclear periphery from the end of mitosis to G1 phase, and this localization depends on the $\mathrm{Ku}-$ and Sirmediated anchoring mechanisms (Hediger et al. 2002; Taddei and Gasser 2004). Prior to anaphase, however, telomeres localize randomly within the nucleus (Laroche et al. 2000; Hediger et al. 2002). It was demonstrated that the delocalization of telomeres from the nuclear periphery is triggered by their DNA replication, which suppresses the Ku-mediated anchoring mechanism in late $\mathrm{S}$ phase (Ebrahimi and Donaldson 2008). The detachment of telomeres from the nuclear periphery probably enhances telomere mobility in the nucleus, which has an advantage in subsequent chromosome segregation. Thus, replication at centromeres and telomeres is closely linked to chromosome segregation in mitosis. This link is probably crucial in budding yeast as it is thought that $\mathrm{S}$ phase and mitosis are overlapped, and G2 phase is absent in this organism (Kitamura et al. 2007).

\section{Conclusions and perspectives}

DNA replication is a spatially regulated process at multiple levels; i.e., from replisome architecture to subnuclear chromosome organization. The spatial regulation of DNA replication is closely linked to its temporal regulation. Both spatial and temporal regulations seem to be important for efficient duplication of chromosomes, for proper responses to replication 
stresses and for coupling DNA replication with other cellular events such as chromosome segregation.

Several new methods have been developed and widely applied over the last decade, making considerable contribution to the research field. For example, genome-wide approaches have introduced unbiased and thorough landscapes of genome replication in yeast and other organisms (Raghuraman et al. 2001; Wyrick et al. 2001; Yabuki et al. 2002; MacAlpine et al. 2004). Single-cell and single-molecule assays have enabled analyses of DNA replication in high spatial and temporal resolution and have opened a window into how DNA replication differs from cell to cell and from chromosome to chromosome (Michalet et al. 1997; Herrick et al. 2000; Kitamura et al. 2006). Further development of these methods and other biochemical, genetic, and cell biological approaches will advance further the research of chromosome duplication.

Acknowledgments We thank Julian Blow and Lesley Clayton for their helpful comments on the manuscript, Kunio Kitada for sharing the detailed data in their genome-wide replication analysis in budding yeast, and Cristina Cardoso for providing a high-resolution image for Fig. 3. Work in our lab has been supported by the funding from The Wellcome Trust, Cancer Research, UK, Lister Research Institute Prize, Human Frontier Science Program, Association for International Cancer Research, and Medical Research Institute. TUT is a senior research fellow of Cancer Research, UK.

Open Access This article is distributed under the terms of the Creative Commons Attribution Noncommercial License which permits any noncommercial use, distribution, and reproduction in any medium, provided the original author(s) and source are credited.

\section{References}

Adachi Y, Laemmli UK (1992) Identification of nuclear prereplication centers poised for DNA synthesis in Xenopus egg extracts: immunolocalization study of replication protein A. J Cell Biol 119:1-15

Adachi Y, Laemmli UK (1994) Study of the cell cycledependent assembly of the DNA pre-replication centres in Xenopus egg extracts. EMBO J 13:4153-4164

Aparicio JG, Viggiani CJ, Gibson DG, Aparicio OM (2004) The Rpd3-Sin3 histone deacetylase regulates replication timing and enables intra-S origin control in Saccharomyces cerevisiae. Mol Cell Biol 24:4769-4780

Baker TA, Bell SP (1998) Polymerases and the replisome: machines within machines. Cell 92:295-305
Bates D, Kleckner N (2005) Chromosome and replisome dynamics in E. coli: loss of sister cohesion triggers global chromosome movement and mediates chromosome segregation. Cell 121:899-911

Bell SP, Dutta A (2002) DNA replication in eukaryotic cells. Annu Rev Biochem 71:333-374

Berezney R, Dubey DD, Huberman JA (2000) Heterogeneity of eukaryotic replicons, replicon clusters, and replication foci. Chromosoma 108:471-484

Berger AB, Cabal GG, Fabre E et al (2008) High-resolution statistical mapping reveals gene territories in live yeast. Nat Meth 5:1031-1037

Bielinsky AK, Gerbi SA (2001) Where it all starts: eukaryotic origins of DNA replication. J Cell Sci 114:643-651

Blow JJ, Dutta A (2005) Preventing re-replication of chromosomal DNA. Nat Rev Mol Cell Biol 6:476-486

Boye E, Lobner-Olesen A, Skarstad K (2000) Limiting DNA replication to once and only once. EMBO Rep 1:479-483

Branzei D, Foiani M (2005) The DNA damage response during DNA replication. Curr Opin Cell Biol 17:568-575

Branzei D, Foiani M (2009) The checkpoint response to replication stress. DNA Repair (Amst) 8:1038-1046

Brewer BJ, Fangman WL (1988) A replication fork barrier at the 3' end of yeast ribosomal RNA genes. Cell 55:637-643

Bussiere DE, Bastia D (1999) Termination of DNA replication of bacterial and plasmid chromosomes. Mol Microbiol 31:1611-1618

Cardoso MC, Leonhardt H, Nadal-Ginard B (1993) Reversal of terminal differentiation and control of DNA replication: cyclin A and Cdk2 specifically localize at subnuclear sites of DNA replication. Cell 74:979-992

Carrozza MJ, Li B, Florens L et al (2005) Histone H3 methylation by Set 2 directs deacetylation of coding regions by Rpd3S to suppress spurious intragenic transcription. Cell 123:581-592

Conti C, Sacca B, Herrick J et al (2007) Replication fork velocities at adjacent replication origins are coordinately modified during DNA replication in human cells. Mol Biol Cell 18:3059-3067

Cosgrove AJ, Nieduszynski CA, Donaldson AD (2002) Ku complex controls the replication time of DNA in telomere regions. Genes Dev 16:2485-2490

Courbet S, Gay S, Arnoult N et al (2008) Replication fork movement sets chromatin loop size and origin choice in mammalian cells. Nature 455:557-560

Dai J, Chuang RY, Kelly TJ (2005) DNA replication origins in the Schizosaccharomyces pombe genome. Proc Natl Acad Sci U S A 102:337-342

Dimitrova DS, Gilbert DM (2000) Temporally coordinated assembly and disassembly of replication factories in the absence of DNA synthesis. Nat Cell Biol 2:686-694

Dimitrova DS, Todorov IT, Melendy T, Gilbert DM (1999) $\mathrm{Mcm} 2$, but not RPA, is a component of the mammalian early G1-phase prereplication complex. J Cell Biol 146:709-722

Dingman CW (1974) Bidirectional chromosome replication: some topological considerations. J Theor Biol 43:187-195

Doksani Y, Bermejo R, Fiorani S, Haber JE, Foiani M (2009) Replicon dynamics, dormant origin firing, and terminal fork integrity after double-strand break formation. Cell 137:247-258 
Ebrahimi H, Donaldson AD (2008) Release of yeast telomeres from the nuclear periphery is triggered by replication and maintained by suppression of Ku-mediated anchoring. Genes Dev 22:3363-3374

Falaschi A (2000) Eukaryotic DNA replication: a model for a fixed double replisome. Trends Genet 16:88-92

Feng W, Collingwood D, Boeck ME et al (2006) Genomic mapping of single-stranded DNA in hydroxyureachallenged yeasts identifies origins of replication. Nat Cell Biol 8:148-155

Ferguson BM, Fangman WL (1992) A position effect on the time of replication origin activation in yeast. Cell 68:333339

Friedman KL, Diller JD, Ferguson BM et al (1996) Multiple determinants controlling activation of yeast replication origins late in S phase. Genes Dev 10:1595-1607

Frouin I, Montecucco A, Spadari S, Maga G (2003) DNA replication: a complex matter. EMBO Rep 4:666-670

Ge XQ, Jackson DA, Blow JJ (2007) Dormant origins licensed by excess Mcm2-7 are required for human cells to survive replicative stress. Genes Dev 21:3331-3341

Gilbert DM (2002) Replication timing and transcriptional control: beyond cause and effect. Curr Opin Cell Biol 14:377-383

Hayashi M, Katou Y, Itoh T et al (2007) Genome-wide localization of pre-RC sites and identification of replication origins in fission yeast. EMBO J 26:1327-1339

Heath IB (1980) Variant mitoses in lower eukaryotes: indication of the evolution of mitosis? Int Rev Cytol 64:1-80

Hediger F, Neumann FR, Van Houwe G, Dubrana K, Gasser SM (2002) Live imaging of telomeres: $y K u$ and Sir proteins define redundant telomere-anchoring pathways in yeast. Curr Biol 12:2076-2089

Herendeen D, Kelly TJ (1996) SV40 DNA replication. In: Blow JJ (ed) Eukaryotic DNA Replication. IRL Press, Oxford, pp 29-65

Herrick J, Bensimon A (2008) Global regulation of genome duplication in eukaryotes: an overview from the epifluorescence microscope. Chromosoma 117:243-260

Herrick J, Stanislawski P, Hyrien O, Bensimon A (2000) Replication fork density increases during DNA synthesis in X. laevis egg extracts. J Mol Biol 300:1133-1142

Heun P, Laroche T, Raghuraman MK, Gasser SM (2001) The positioning and dynamics of origins of replication in the budding yeast nucleus. J Cell Biol 152:385-400

Hiraga S, Hagihara-Hayashi A, Ohya T, Sugino A (2005) DNA polymerases alpha, delta, and epsilon localize and function together at replication forks in Saccharomyces cerevisiae. Genes Cells 10:297-309

Hiraga S, Robertson ED, Donaldson AD (2006) The Ctf18 RFC-like complex positions yeast telomeres but does not specify their replication time. EMBO J 25:1505-1514

Hiratani I, Takebayashi S, Lu J, Gilbert DM (2009) Replication timing and transcriptional control: beyond cause and effect — part II. Curr Opin Genet Dev 19:142-149

Hozák P, Hassan AB, Jackson DA, Cook PR (1993) Visualization of replication factories attached to nucleoskeleton. Cell 73:361-373

Jackson DA, Pombo A (1998) Replicon clusters are stable units of chromosome structure: evidence that nuclear organization contributes to the efficient activation and propagation of S phase in human cells. J Cell Biol 140:1285-1295
Jackson PK, Chevalier S, Philippe M, Kirschner MW (1995) Early events in DNA replication require cyclin $\mathrm{E}$ and are blocked by p21CIP1. J Cell Biol 130:755-769

Jensen RB, Wang SC, Shapiro L (2001) A moving DNA replication factory in Caulobacter crescentus. EMBO J 20:4952-4963

Johnson A, O'Donnell M (2005) Cellular DNA replicases: components and dynamics at the replication fork. Annu Rev Biochem 74:283-315

Kadosh D, Struhl K (1997) Repression by Ume6 involves recruitment of a complex containing $\operatorname{Sin} 3$ corepressor and Rpd3 histone deacetylase to target promoters. Cell 89:365-371

Keogh MC, Kurdistani SK, Morris SA et al (2005) Cotranscriptional Set 2 methylation of histone $\mathrm{H} 3$ lysine 36 recruits a repressive Rpd3 complex. Cell 123:593-605

Kitamura E, Blow JJ, Tanaka TU (2006) Live-cell imaging reveals replication of individual replicons in eukaryotic replication factories. Cell 125:1297-1308

Kitamura E, Tanaka K, Kitamura Y, Tanaka TU (2007) Kinetochore microtubule interaction during $\mathrm{S}$ phase in Saccharomyces cerevisiae. Genes Dev 21:3319-3330

Knott SR, Viggiani CJ, Tavaré S, Aparicio OM (2009) Genome-wide replication profiles indicate an expansive role for $\mathrm{Rpd} 3 \mathrm{~L}$ in regulating replication initiation timing or efficiency, and reveal genomic loci of Rpd3 function in Saccharomyces cerevisiae. Genes Dev 23:1077-1090

Laroche T, Martin SG, Tsai-Pflugfelder M, Gasser SM (2000) The dynamics of yeast telomeres and silencing proteins through the cell cycle. J Struct Biol 129:159-174

Lemon KP, Grossman AD (1998) Localization of bacterial DNA polymerase: evidence for a factory model of replication. Science 282:1516-1519

Lemon KP, Grossman AD (2000) Movement of replicating DNA through a stationary replisome. Mol Cell 6:1321-1330

Lengronne A, Pasero P, Bensimon A, Schwob E (2001) Monitoring S phase progression globally and locally using BrdU incorporation in $\mathrm{TK}(+)$ yeast strains. Nucleic Acids Res 29:1433-1442

Leonhardt H, Rahn HP, Weinzierl P et al (2000) Dynamics of DNA replication factories in living cells. J Cell Biol 149:271-280

Ligasová A, Raška I, Koberna K (2008) Organization of human replicon: singles or zipping couples? J Struct Biol 165 (3):204-213

Linskens MH, Huberman JA (1988) Organization of replication of ribosomal DNA in Saccharomyces cerevisiae. Mol Cell Biol 8:4927-4935

Ma H, Samarabandu J, Devdhar RS et al (1998) Spatial and temporal dynamics of DNA replication sites in mammalian cells. J Cell Biol 143:1415-1425

MacAlpine DM, Rodriguez HK, Bell SP (2004) Coordination of replication and transcription along a Drosophila chromosome. Genes Dev 18:3094-3105

Maya-Mendoza A, Petermann E, Gillespie DA, Caldecott KW, Jackson DA (2007) Chk1 regulates the density of active replication origins during the vertebrate $\mathrm{S}$ phase. EMBO J 26:2719-2731

McCarroll RM, Fangman WL (1988) Time of replication of yeast centromeres and telomeres. Cell 54:505-513 
McCune HJ, Danielson LS, Alvino GM et al (2008) The temporal program of chromosome replication: genomewide replication in clb5 $\delta$ Saccharomyces cerevisiae. Genetics 180(4):1833-1847

McNeil JB, Friesen JD (1981) Expression of the Herpes simplex virus thymidine kinase gene in Saccharomyces cerevisiae. Mol Gen Genet 184:386-393

Meister P, Taddei A, Vernis L et al (2005) Temporal separation of replication and recombination requires the intra-S checkpoint. J Cell Biol 168:537-544

Meister P, Taddei A, Ponti A, Baldacci G, Gasser SM (2007) Replication foci dynamics: replication patterns are modulated by S-phase checkpoint kinases in fission yeast. EMBO J 26:1315-1326

Michaelis C, Ciosk R, Nasmyth K (1997) Cohesins: chromosomal proteins that prevent premature separation of sister chromatids. Cell 91:35-45

Michalet X, Ekong R, Fougerousse F et al (1997) Dynamic molecular combing: stretching the whole human genome for high-resolution studies. Science 277:1518-1523

Migocki MD, Lewis PJ, Wake RG, Harry EJ (2004) The midcell replication factory in Bacillus subtilis is highly mobile: implications for coordinating chromosome replication with other cell cycle events. Mol Microbiol 54:452-463

Nakamura H, Morita T, Sato C (1986) Structural organizations of replicon domains during DNA synthetic phase in the mammalian nucleus. Exp Cell Res 165:291-297

Nakayasu H, Berezney R (1989) Mapping replicational sites in the eucaryotic cell nucleus. J Cell Biol 108:1-11

Natsume T, Tsutsui Y, Sutani T et al (2008) A DNA polymerase alpha accessory protein, Mcl1, is required for propagation of centromere structures in fission yeast. PLoS ONE 3:e2221

Newlon CS, Theis JF (1993) The structure and function of yeast ARS elements. Curr Opin Genet Dev 3:752-758

Nick McElhinny SA, Gordenin DA, Stith CM, Burgers PM, Kunkel TA (2008) Division of labor at the eukaryotic replication fork. Mol Cell 30:137-144

Nieduszynski CA, Knox Y, Donaldson AD (2006) Genomewide identification of replication origins in yeast by comparative genomics. Genes Dev 20:1874-1879

Ohya T, Kawasaki Y, Hiraga S et al (2002) The DNA polymerase domain of pol $\varepsilon$ is required for rapid, efficient, and highly accurate chromosomal DNA replication, telomere length maintenance, and normal cell senescence in Saccharomyces cerevisiae. J Biol Chem 277:28099-28108

Pasero P, Braguglia D, Gasser SM (1997) ORC-dependent and origin-specific initiation of DNA replication at defined foci in isolated yeast nuclei. Genes Dev 11:1504-1518

Pursell ZF, Isoz I, Lundstrom EB, Johansson E, Kunkel TA (2007) Yeast DNA polymerase epsilon participates in leading-strand DNA replication. Science 317:127130

Raghuraman MK, Brewer BJ, Fangman WL (1997) Cell cycledependent establishment of a late replication program. Science 276:806-809
Raghuraman MK, Winzeler EA, Collingwood D et al (2001) Replication dynamics of the yeast genome. Science 294:115-121

Reyes-Lamothe R, Possoz C, Danilova O, Sherratt DJ (2008) Independent positioning and action of Escherichia coli replisomes in live cells. Cell 133:90-102

Robinson NP, Bell SD (2005) Origins of DNA replication in the three domains of life. FEBS J 272:3757-3766

Sadoni N, Cardoso MC, Stelzer EH, Leonhardt H, Zink D (2004) Stable chromosomal units determine the spatial and temporal organization of DNA replication. J Cell Sci 117:5353-5365

Somanathan S, Suchyna TM, Siegel AJ, Berezney R (2001) Targeting of PCNA to sites of DNA replication in the mammalian cell nucleus. J Cell Biochem 81:56-67

Sporbert A, Gahl A, Ankerhold R, Leonhardt H, Cardoso MC (2002) DNA polymerase clamp shows little turnover at established replication sites but sequential de novo assembly at adjacent origin clusters. Mol Cell 10:13551365

Stevenson JB, Gottschling DE (1999) Telomeric chromatin modulates replication timing near chromosome ends. Genes Dev 13:146-151

Straight AF, Belmont AS, Robinett CC, Murray AW (1996) GFP tagging of budding yeast chromosomes reveals that protein-protein interactions can mediate sister chromatid cohesion. Curr Biol 6:1599-1608

Taddei A, Gasser SM (2004) Multiple pathways for telomere tethering: functional implications of subnuclear position for heterochromatin formation. Biochim Biophys Acta 1677:120-128

Vernis L, Piskur J, Diffley JF (2003) Reconstitution of an efficient thymidine salvage pathway in Saccharomyces cerevisiae. Nucleic Acids Res 31:e120

Vogelauer M, Rubbi L, Lucas I, Brewer BJ, Grunstein M (2002) Histone acetylation regulates the time of replication origin firing. Mol Cell 10:1223-1233

Waga S, Stillman B (1998) The DNA replication fork in eukaryotic cells. Annu Rev Biochem 67:721-751

Wessel R, Schweizer J, Stahl H (1992) Simian virus 40 T-antigen DNA helicase is a hexamer which forms a binary complex during bidirectional unwinding from the viral origin of DNA replication. J Virol 66:804-815

Wyrick JJ, Aparicio JG, Chen T et al (2001) Genome-wide distribution of ORC and MCM proteins in S. cerevisiae: high-resolution mapping of replication origins. Science 294:2357-2360

Yabuki N, Terashima H, Kitada K (2002) Mapping of early firing origins on a replication profile of budding yeast. Genes Cells 7:781-789

Yan H, Newport J (1995) An analysis of the regulation of DNA synthesis by cdk2, Cip1, and licensing factor. J Cell Biol 129:1-15

Zappulla DC, Sternglanz R, Leatherwood J (2002) Control of replication timing by a transcriptional silencer. Curr Biol 12:869-875 